\title{
Predictive accuracy of CURB-65 as comparedto PSI scorein the severity assessment of community acquired pneumonia
}

\author{
Praveen G.S. ${ }^{1}$, Fathahudeen. A. ${ }^{2 *}$, S. Nair R. ${ }^{3}$, Kumari K A. ${ }^{4}$, Nair S. ${ }^{5}$, Moosan H. ${ }^{6}$, Vishnu R. ${ }^{7}$ \\ DOI: https://doi.org/10.17511/ijmrr.2019.i03.06 \\ 1 Praveen G.S, Department of Pulmonary Medicine, Govt Medical College, Thiruvananthapuram, Kerala, India. \\ 2* Fathahudeen. A, Department of Pulmonary Medicine, Govt Medical College, Ernakulam, Kerala, India. \\ ${ }^{3}$ Reshmi S. Nair, Department of Pulmonary Medicine, Govt Medical College, Thiruvananthapuram, Kerala, India. \\ ${ }^{4}$ Anitha Kumari K, Department of Pulmonary Medicine, Govt Medical College, Thiruvananthapuram, Kerala, India. \\ 5 Sanjeev Nair, Department of Pulmonary Medicine, Govt Medical College, Thiruvananthapuram, Kerala, India. \\ 6 Hisham Moosan, Achutha Menon Centre for Health Sciences and Technology, Thiruvananthapuram, Kerala, India. \\ 7 Vishnu R, Department of Radiodiagnosis, Govt Medical College, Thiruvananthapuram, Kerala, India.
}

Introduction: Pneumonia Severity Index (PSI) and CURB-65 rule for community acquired pneumonia (CAP) have been developed to stratify patients based on mortality. Lack of a risk stratifying score like PSI or CURB-65 can lead to significant delay in starting treatment. This study was conducted to find out the ability of CURB-65 score and PSI to predict clinically relevant outcomes. Methods: 78 patients diagnosed as CAP admitted to a tertiary care hospital were enrolled into the study. Detailed clinical history was noted and CURB-65 and PSI scores were given with the help of a structured questionnaire in $<24$ hours of admission. The patients were revisited at day 3 and at discharge and data collected. Results:Out of 78 patients included in the study, 60 were males and 18 were females. Of the 78 patients, 14 died accounting for aninhospital mortality of $17.94 \%$. Mortality in the mild, moderate and severe groups of CURB-65 were $0 \%, 16.7 \%$ and $47.8 \%$ respectively. Mortality in the mild, moderate and severe groups of PSI were $1.8 \%, 50 \%$ and $80 \%$ respectively. Area under the curve (AUC) for CURB-65 and PSI in terms of in hospital mortality were 0.935 and 0.920 respectively. Conclusion: The CURB-65 and PSI scores correlated well with mortality and other severity indicators. The CURB-65 has a better discriminatory power than PSI inour study. Because of its simplicity in addition to its better discriminatory power than PSI, CURB65 may be better suited as a severity scoring system in CAP.

Keywords: CAP, CURB-65, in-hospital mortality, PSI

Corresponding Author

Fathahudeen. A, Department of Pulmonary Medicine, Govt Medical College, Ernakulam, Kerala, India. Email: praveenchest@gmail.com
How to Cite this Article

To Browse
Praveen GS, Fathahudeen A, Nair RS, Kumari K A, Nair S, Moosan H, Vishnu R. Predictive accuracy of CURB-65 as comparedto PSI scorein the severity assessment of community acquired pneumonia. Int J Med Res Rev. 2019;7(3):182-189.

Available From

https://ijmrr.medresearch.in/index.php/ijmrr/article/

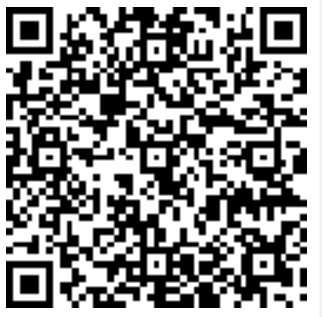
view/1056

\begin{tabular}{|c|c|}
\hline $\begin{array}{c}\text { Manuscript Received } \\
2019-04-26\end{array}$ & $\begin{array}{c}\text { Review Round } 1 \\
2019-05-04\end{array}$ \\
\hline $\begin{array}{c}\text { Conflict of Interest } \\
\text { No }\end{array}$ & $\begin{array}{c}\text { Funding } \\
\mathrm{Nil}\end{array}$ \\
\hline
\end{tabular}

(c) 2019 by Praveen G.S, Fathahudeen. A, Reshmi S. Nair, Anitha Kumari K, Sanjeev Nair, Hisham Moosan, Vishnu R and

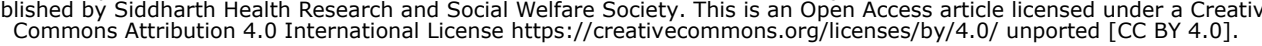

$\begin{array}{lc}\begin{array}{c}\text { Review Round } 2 \\ 2019-05-10\end{array} & \text { Review Round } 3 \\ \begin{array}{c}\text { Ethical Approval } \\ \text { Yes }\end{array} & \begin{array}{c}\text { Plagiarism X-checker } \\ 7 \%\end{array} \\ \text { ir, Anitha Kumari K, Sanjeev Nair, Hisham Moosan, Vishnu R and } \\ \text { e Society. This is an Open Access article licensed under a Creative } \\ \text { //creativecommons.org/licenses/by/4.0/ unported [CC BY 4.0]. }\end{array}$

Accepted 2019-05-14

Note 


\section{Introduction}

Pneumonia is an inflammation of the lung tissue due to an infectious agent. Community acquired pneumonia (CAP) refers to pneumonia acquired outside of hospital or extended care facilities. CAP have an incidence of about $20 \%$ to $30 \%$ in developing countries ascompared to $3 \%$ to $4 \%$ in developed countries[1]. The incidence varies markedly with age, being much higher in the extremes of age [2].

The causative agent in CAP is often difficult to establish. Even after extensive investigations; aetiological confirmation was achieved in not morethan $45 \%$ to $70 \%$ of patients [3]. Streptococcus pneumoniae is the most commonly isolated pathogen responsible for $35 \%$ of patients. It is followed by Klebsiella pneumonia (22\%), staphylococcus aureus (17\%), mycoplasma (15\%), Escherichia Coli $(11 \%)$, beta hemolytic streptococci $(7.5 \%)$ and other gram negative bacteria (9\%) [4]. The morbidity and mortality levels vary significantly with the severity of the disease. CAP is one of the commonlife threatening infections, which results in deaths mostly in the developing countries [5]. The mortality in a study of CAP reported by Bansal et al [4] in India is 11 percent. The symptoms of CAP can range from mild to severe. The commons symptoms arefever $(95.1 \%)$ followed by cough $(75.7 \%)$ and breathlessness (65\%) [6].

The knowledge of relevant prognostic factors might be useful for early identification of patients at high risk who requires intensive treatment. Prognostic scoring systems, such as pneumonia severity index (PSI) and the CURB-65 rule for CAP have been developed to address these issues. The most widely studied predictive model in CAP is the PSI score developed in USA. It is based on 20 variables that are used to derive a score which enables patient to be stratified in to five, risk categories [figure 2] The major limitation of PSI is the complexity involved in the calculation of the score. The CURB-65 score is based on the clinical information available at initial hospital assessment [figure 1]. This enables patients to be stratified according to increasing risk of mortality. However, the major deficiency of the CURB-65 approach is that it does not generally account for comorbid illness. Even though most of the burden in terms of mortality and morbidity occurs in under developed countries, not enough studies are availableto study the factors associated with an adverse prognosis of CAP in this region.
Our study aims to test the validity of PSI and CURB65 severity scoring systems in CAP in an Indian setting in a tertiary care hospital.

\section{Materials and Methods}

Study setting: Department of Pulmonary Medicine, Government Medical College, Thiruvananthapuram, Kerala, India

Study design: Prospective observational cohort study.

Study population: Patients who fulfilled the criteria for CAP and admitted in the department of Pulmonary Medicine, Government Medical College, Thiruvananthapuram, Kerala, India.

Study period: 1 year.

\section{Inclusion criteria}

- Subjects of age 12 years and above.

- CAP diagnosed based on CXR lesion consistent with consolidation and any two out of fever,cough, breathlessness and pleuritic type chest pain.

- Exclusion criteria:

- Pulmonary Tuberculosis

- Hospital acquired pneumonia

- HIV positive patients

- Patients on cancer chemotherapy

Study methodology: The patients were admitted at the discretion ofattending Pulmonologist and empirical antibiotics started according to the hospital guidelines. The antibiotics were changed according to the blood and sputum culture reports if required. The need for ICU admissionand also the need for mechanical ventilation were decided by the concerned Pulmonologist according to the hospital guidelines.

78 patients were included in the study. They were evaluated with a structured paper based questionnaire within 24 hours of admission (visit1) and were scored with CURB-65 and PSI. Clinical details were obtained at 72 hours of admission (visit 2) and then at discharge or death (visit 3). During these visits clinical status, need for ICU admission and mechanical ventilation and mortality noted. The patients were divided into mild, moderate and severe groups based on CURB-65 and PSI according to guidelines, by the primary investigator. 
Those with CURB-65 scores 0 and 1 were grouped mild, 2 as moderate and scores 3,4 and 5 as severe. CAP patients with PSI risk class I, II, III were grouped as mild, PSI risk class IVas moderate and risk class $\mathrm{V}$ as severe.

Statistical analysis: Data was coded and entered in Microsoft Excel and statistical analysis was performed using Epiinfo software and SPSS (version10.0).Descriptive statistics of sociodemographic and clinical variables included frequencies, percentages, means and standard deviations. Receiver operating characteristic curves were calculated to evaluate how well the scores discriminated between patients who survived CAP and those who died, values for other parameters like need for ICU care and mechanical ventilation were also determined. The area under the curve (AUC) and 95\% confidence intervals were obtained. A two-tailed p-value $<0.05$ was considered statistically significant.

Ethical Considerations: Clearance from the institutional ethical committee was obtained prior to the study. All the study participants weregiven subject information sheet along with a verbal briefing about the study and those who gave their written consent were only included in the study. At most care was taken to see that no personal identifiers in any form pertaining to the study participants were disclosed at any stage of this study

\section{Scoring systems used}

\section{CURB-65 SCORE}

\begin{tabular}{|l|l|}
\hline \multicolumn{1}{|c|}{ Initial } & \multicolumn{1}{c|}{ Description } \\
\hline C & Mental confusion \\
\hline U & Blood Urea $>7 \mathrm{mmol} / \mathrm{L}$ \\
\hline R & Respiratory rate $>=30 / \mathrm{min}$ \\
\hline B & $\begin{array}{l}\text { Low Blood pressure } \\
\text { Diastolic blood pressure }<60 \mathrm{mmHg} \\
\text { Systolic blood pressure }>90 \mathrm{mmHg}\end{array}$ \\
\hline 65 & Age $>=65$ \\
\hline
\end{tabular}

\section{PSI SCORE}

\begin{tabular}{|l|l|}
\hline \multicolumn{1}{|c|}{ Characteristic } & \multicolumn{1}{|c|}{ Points Assigned } \\
\hline Demographic Factor & Age $(\mathrm{yr})$ \\
\hline Age & Age $(\mathrm{yr})-10$ \\
& +10 \\
\hline Men & \\
Women & +30 \\
Nursing home resident & +20 \\
\hline Coexisting illness & \\
\hline Neoplastic disease &
\end{tabular}

\begin{tabular}{|c|c|c|c|c|c|}
\hline \multicolumn{5}{|c|}{ Congestive heart failure } & +10 \\
\hline \multicolumn{5}{|c|}{ Cerebrovascular disease } & +10 \\
\hline \multicolumn{5}{|c|}{ Renal Disease } & +10 \\
\hline \multicolumn{6}{|c|}{ Physical- examination findings } \\
\hline \multicolumn{5}{|c|}{ Altered mental status } & +20 \\
\hline \multicolumn{5}{|c|}{ Respiratory rate $>30 / \mathrm{min}$} & +20 \\
\hline \multicolumn{5}{|c|}{ Systolic blood pressure $<90 \mathrm{~mm} \mathrm{Hg}$} & +20 \\
\hline \multicolumn{5}{|c|}{ Temperature $<35 \circ \mathrm{C}$ or $>40 \mathrm{oC}$} & +15 \\
\hline \multicolumn{5}{|c|}{ Pulse $>125 / \mathrm{min}$} & +10 \\
\hline \multicolumn{6}{|c|}{ Laboratory and Radiographic Findings } \\
\hline \multicolumn{5}{|c|}{ Arterial $\mathrm{pH}<7.35$} & +30 \\
\hline \multicolumn{5}{|c|}{ Blood urea nitrogen $>30 \mathrm{mg} / \mathrm{dl}(11 \mathrm{mmol} /$ liter $)$} & +20 \\
\hline \multicolumn{5}{|c|}{ Sodium $<130 \mathrm{mmol} / \mathrm{liter}$} & +20 \\
\hline \multicolumn{5}{|c|}{ Glucose $>250 \mathrm{mg} / \mathrm{dl}(14 \mathrm{mmol} / \mathrm{liter})$} & +10 \\
\hline \multicolumn{5}{|c|}{ Haematocrit $<30 \%$} & +10 \\
\hline \multicolumn{5}{|c|}{$\mathrm{PaO} 2<60 \mathrm{~mm} \mathrm{Hg}$ or Oxygen saturation $<90 \%$} & +10 \\
\hline \multicolumn{5}{|c|}{ Pleural effusion } & +10 \\
\hline Risk & Low & Low & Low & Medium & High \\
\hline Class & I & II & III & IV & v \\
\hline Score & $<51$ & $51-70$ & $71-90$ & $91-130$ & $>130$ \\
\hline
\end{tabular}

\section{Results}

Table-1: showing sex distribution and mean age.

\begin{tabular}{|l|l|l|l|}
\hline \multirow{2}{*}{ Sex } & \multirow{2}{*}{ N } & \multicolumn{2}{c|}{ Age In Years } \\
\cline { 3 - 4 } & & Mean & SD \\
\hline Female & 18 & 58.28 & 10.71 \\
\hline Male & 60 & 57.52 & 17.06 \\
\hline Total & 78 & 57.69 & 15.76 \\
\hline
\end{tabular}

In our study, out of 78 patients diagnosed with CAP, $60(76.92 \%)$ were males and $18(23.07 \%)$ were females [Table 1]. The mean age was 57.69 years. The maximum number of patients, 24(30.7\%) were in the age group of $61-70$ years followed by 23 patients $(29.4 \%)$ in the $41-50$ year age group. Only $34(43.58 \%)$ patients were below 50 years of age. $44(56.41 \%)$ patients were above 50 years of age.

Table-2: Showing the patient distribution for mild, moderate and severe groups of CURB-65 \begin{tabular}{|l|l|l|l|l|}
\hline CURB -65 & n & Inhospital mortality & Mechanical ventilation & ICU ADM \\
\hline
\end{tabular}

\begin{tabular}{|c|c|c|c|c|c|c|}
\hline & n & $\%$ & n & $\%$ & n & $\%$ \\
\hline Mild & $37 \mid 0$ & 0 & 0 & 0 & 0 & 0 \\
\hline Moderate & 183 & 16.7 & 3 & 16.7 & 7 & 38.9 \\
\hline Severe & 2311 & 47.8 & 9 & 39.1 & 16 & 69.6 \\
\hline p & \multicolumn{2}{|c|}{$\mid<0.001$} & \multicolumn{2}{|c|}{$<0.001$} & \multicolumn{2}{|c|}{$<0.001$} \\
\hline
\end{tabular}

ICU ADM-ICU admission

Maximum mortality rates were noted in the severe group.The subjects were given CURB-65 scoring and were grouped into mild, moderate and severe. 
The scores 0 and 1 were included in mild group, score 2 in moderate group, scores 3, 4,5 in severe group. Out of 68 patients, 37 were in mild group, 18 in moderate group and 23 in severe group.

Various prognostic parameters like need for ICU admission, need for mechanical ventilation and inhospital mortality were noted separately for mild, moderate and severe groups of CURB-65 and depicted in table 2 .

Table-3: Showing the patient distribution for mild, moderate and severe groups of PSI

\begin{tabular}{|l|l|l|l|l|l|l|l|}
\hline \multirow{2}{*}{ PSI } & \multirow{2}{*}{$\mathrm{n}$} & In hospital mortality & \multicolumn{2}{|l|}{ Mechanical ventilation } & \multicolumn{2}{|l|}{ ICU ADM } \\
\cline { 2 - 8 } & & $\mathrm{n}$ & $\%$ & $\mathrm{n}$ & $\%$ & $\mathrm{n}$ & $\%$ \\
\hline Mild & 55 & 1 & 1.8 & 1 & 1.8 & 8 & 14.5 \\
\hline Moderate & 18 & 9 & 50 & 9 & 50 & 10 & 55.6 \\
\hline Severe & 5 & 4 & 80 & 2 & 40 & 5 & 100 \\
\hline $\mathrm{P}$ & \multicolumn{2}{|l|}{$<0.001$} & \multicolumn{2}{|l|}{$<0.001$} & $<0.001$ \\
\hline
\end{tabular}

ICU ADM-ICU admission

Maximum mortality rates were noted in the severe group.

The subjects were given PSI scoring and were grouped into mild, moderate and severe. Out of 68 patients, 55 were in mild group, 18 in moderate group and 5 in severe group.

Various prognostic parameters like need for ICU admission, need for mechanical ventilation and inhospital mortality were noted separately for mild, moderate and severe groups of PSI score and depicted in table 3 .

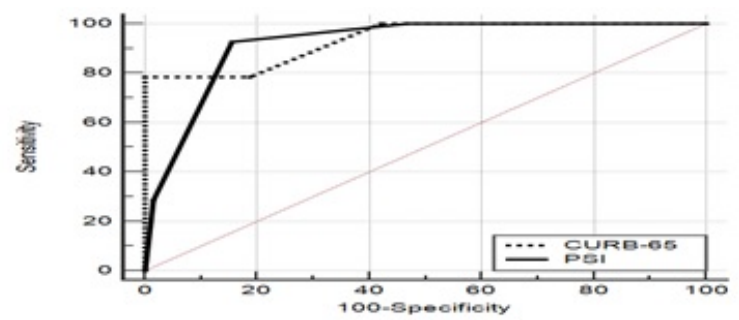

\begin{tabular}{|l|l|l|l|}
\hline & AUC & SEa & $95 \%$ CIb \\
\hline CURB-65 & 0.935 & 0.0362 & 0.855 to 0.978 \\
\hline PSI & 0.920 & 0.0291 & 0.836 to 0.969 \\
\hline
\end{tabular}

Figure-3: ROC curve for PSI and CURB-65 with inpatient mortality as outcome

The Area under the Curve (AUC) was more for CURB-65(0.935) as compared to PSI (0.920) when in-patient mortality is considered.

The CURB-65 has a better discriminatory power than PSI as far as the in-patient mortality is considered.

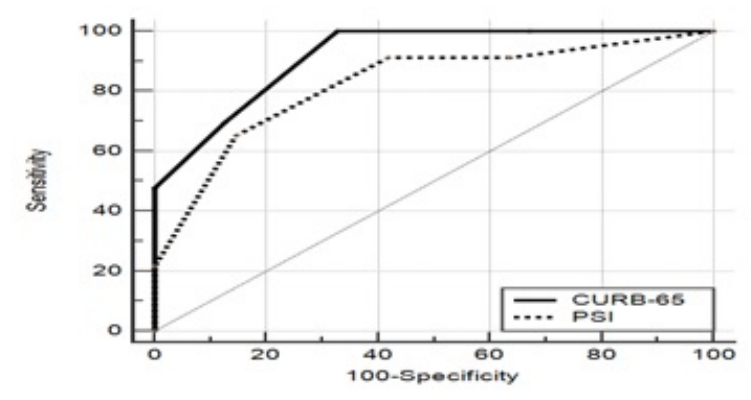

\begin{tabular}{|l|l|l|l|}
\hline & AUC & SEa & $95 \%$ CIb \\
\hline CURB_65 & 0.917 & 0.0283 & 0.832 to 0.967 \\
\hline PSI & 0.824 & 0.0534 & 0.721 to 0.901 \\
\hline
\end{tabular}

Figure-4: ROC curve for PSI and CURB-65 with ICU admission as outcome

The Area under the Curve (AUC) was more for CURB-65 (0.917) as compared to PSI (0.824) when ICU admission is considered. The CURB-65 has a better discriminatory power than PSI as far as the need for ICU admission is considered.

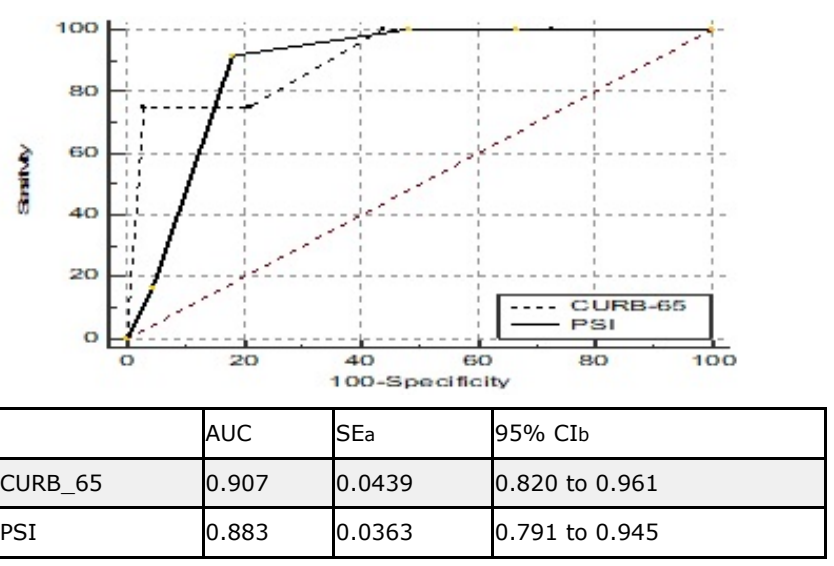

Figure-5: ROC curve for PSI and CURB-65 with need for mechanical ventilation as outcome

The Area under the Curve (AUC) was more for CURB-65(0.907) as compared to PSI (0.883) when need for mechanical ventilation is considered. The CURB-65 has a better discriminatory power than PSI as far as the need for mechanical ventilation is considered.

\section{Discussion}

CAP is a major public health issue with significant morbidity and mortality levels in both developed and developing countries, more so in developing countries. The morbidity and mortality levels vary significantly with the severity of the disease. There has been good evidence that using a severity assessment scoring system can help the prompt treatment of CAP patients and proper utilization of resources. 
This is particularly important in developing countries like India where there is scarcity of resources both human and economic. It has effects onboth the level of treatment received by the patient as well as the overall expense related totreatment [7]. The first landmark study to prognosticate patients of CAP was conducted by the Research Committee of the BTS. Then formulated rules were transformed into a risk scoreby Lim and co-workers in 2002 at the university of Nottingham [8].

The scoring system consists of a six-point score determined at the time of initial presentation. In the original study, mortality risk in the six separate groups was as follows: group 0, $0.7 \%$; group 1 , $3.2 \%$; group 2, 3\%; group 3, $17 \%$; group 4, $42 \%$; and group 5, 57 percent. In 1997, Fine et al [9] introduced the pneumonia severity index (PSI), a product of the Pneumonia PORT study of ambulatory and hospitalized patients with CAP.

The rule stratifies patients into five classes of risk for death within 30 days of presentation. The lowest risk class (risk class I) comprises patients who are younger than 50 years of age, have none of the five important coexisting illnesses and have normal mental status and normal or only mildly abnormal vital signs at presentation.

Assignment to the remaining risk classes depends on the presence or absence of a set of medical history, physical examination, and laboratory findings [table 2]. Mortality rates in risk classes I, II, and III were low $(0.1 \%$ to $0.4 \%$ in class I and $0.9 \%$ to $2.8 \%$ in class III), with correspondingly higher mortality rates in risk classes IV and V. The cumulative mortality rate of patients in risk classes I to III is less than one percent.

The variables in PORT study were derived from and validated in more than 50,000 patients, the largest database ever studied in the history of CAP research. A major limitation of the PSI is the unbalanced impact of age on the score, resulting in a potential under-estimation of severe pneumonia, particularly in younger otherwise healthy individuals [10].

Capelastegui et al [11] presented a comparative validation of the CURB-65, CRB-65 (which omits the blood urea measurement) and PSI scores in a population of 1,776 patients including 676 outpatients. The 30-day mortality increased with increasing score, and predictions of 30-day mortality were equivalent for all scores as assessed by ROC analysis.
This is in contrast to the study by Aujesky et al[12] comprising 3,181 patients and including 1,094 outpatients, showing a minor but significant advantage for the PSI score in predicting 30-day mortality using area under the curve (AUC) analysis. Our study showed a better discriminatory power as evidenced by the AUC for all the three parameters considered. The CURB-65 score has a major advantage in its simplicity. The CURB-65 include confusion and raised urea ( $>7 \mathrm{mmol} / L$ ) in the severity criteria, which may be less useful in the elderly as both conditions are common in acutely unwell older people [13].

In a study by Loh et al [14] conducted in Malaysia, BTS criteria fared poorly in predicting mortality compared with clinical assessment by attending clinicians. These results have demonstrated the need for testing the validity of such scoring systems in developing countries of the world that have different demographic characteristics as well as healthcare delivery systems than the developed countrieswhere such prognostic scoring systems were developed and validated.

The comparison between mortality rates in different risk classes in our study and that of the previous studies $[9],[10],[11],[15]$ showed that in all the studies mortality rates progressively increase with increasing risk scores in both PSI and CURB-65 risk classes. Comparison of mortality rates in different CURB-65 risk classes in our study and that of Capelastegui et al [11] and Ewig et al [10] showed comparable results.

The two scoring systems are viewed as being comple-mentary, as each has different strengths and weaknesses. The PSI seems to have been developed, and best validated, as a way to identify low mortality risk patients, but the scoring system can occasionally underestimate severity of illness, especially in young patients without comorbid illness[15],[16].

This is primarily because the PSI heavily weighs age and comorbidity than the CAP-specific disease severity. In contrast, the CURB-65 approach may be ideal for identifying high mortality risk patients with severe illness due to CAP who might otherwise be overlooked without formal assessment of subtle aberrations in key vital signs [17].However, onedeficiency of the CURB-65 approach is that it does notaccount for comorbid illness, and thus may not be easily applied in elderly patients who may still have substantial mortality risk. 
Thus, both tools offer a valuable assessment of patient illness, but from different perspectives, and each is best at identifying patients at opposite ends of the disease severity.

Reviewing the literature, many studies are available which compares the discriminatory power of different everity assessment scores. Study by Aujesky et al showed PSI has got a higher discriminatory power for predicting mortality compared to CURB 65 score[12]. Busing et al study showed PSI and CURB 65 scores are equally powerful as prediction tools for mortality and need for mechanical ventilation [15]. Little information is available from India regarding prognostic factors in patients with community acquired pneumonia (CAP).

Shah BA et al showed both PSI and CURB-65 were found to have equal sensitivity to predict death from CAP. Specificity of CURB-65 was higher than that of PSI. However, PSI was more sensitive in predicting ICU admission than CURB-65. Study done by Khan et al concluded PSI as a good predictor of mortality, need of ICU admission and mechanical ventilation [18].

In our study both the scoring systems accurately classify CAP patients into different management groups based on in-patient mortality, need for ICU admission and mechanical ventilation with statistical significance. The CURB 65 has got the maximum AUC and hence better discriminatory power than the PSI score in all the three parameters. There are a few limitations of this study. The sample size in our study was small. Our study was conducted in a single tertiary care centre and hence the sample population might not represent the general population.

\section{Conclusion}

CAP patients in the mildgroup ofCURB 65 and PSI are at very low risk of mortality and lowest rates of ICU admission and mechanical ventilation, thus may be suitable for outpatient management. Patients in the moderate groups who are at intermediate risk of mortality should be considered for inpatient management. Patients in the severe groups who are at high risk of mortality and maximum rates of ICU admission and mechanical ventilation should be managed as having severe pneumonia in high dependency units.
The CURB 65 scoring system is simpler to use andhas got a better discriminatory power as far as inpatient mortality rates and other parameters like need for ICU admission and mechanical ventilation areconsidered. CURB 65may be considered as a valuable tool in the busy emergency medicineand pulmonology units.

\section{Author contribution}

Dr Praveen GS was the primary investigator in the study and the study was guided by $\operatorname{Dr} A$. Fathahudeen and $\mathrm{Dr}$ Reshmi $\mathrm{S}$ Nair. Prof Dr Anithakumari and Dr Sanjeev Nair were instrumental with proper advice from the very beginning of the study and their contribution to the study is invaluable. Mr Vishnu $\mathrm{R}$ and $\mathrm{Dr}$ Hisham Moosan helped in manuscript preparation and analysis.

\section{What this study adds to existing knowledge?}

It has been unequivocally proven that various scoring systems in Pneumonia will lead to effective utilization of resources thereby save life and money. Many of the studies available are from the west and other affluent countries. Only limited number of studies are available from developing countries like India where the scoring systems in CAP are urgently needed [1][19]. So this study which gives promising results should be taken into account and further large prospective trials should be followed.

\section{Acknowledgement}

I hereby acknowledge the help rendered by $\mathrm{Dr}$ Sreekala C and Dr Tony of Govt Medical College Thiruvananthapuram and also I would like to mention The University of Kerala.

\section{Reference}

01. Shah BA, Ahmed W, Dhobi GN, et al. Validity of pneumonia severity index and CURB-65 severity scoring systems in community acquired pneumonia in an Indian setting. Indian J Chest Dis Allied Sci. 2010 Jan-Mar;52(1)9-17. [Crossref]

02. Lim WS, Baudouin SV, George RC, Hill AT, et al. BTS guidelines for the management of com munity acquired pneumonia in adults- update 2009. Thorax. 2009 Oct;64(Suppl 3)iii1-55.

doi: $10.1136 /$ thx. 2009.121434 [Crossref] 
03. Lieberman D, Schalaeffer F, Boldur I, Liebermam D, Horowitz, Friedman MG, et al. Multiple pathogens in adult patients admitted with community acquired pneumonia- a one year prospective study of 346 consecutive patients. Thorax. 1996;51(2)179-84.

DOI: $10.1136 /$ thx.51.2.179 [Crossref]

04. Bansal S, Kashyap S, Pal LS, et al. Clinical and bacteriological profile of community acquired pn umonia in Shimla, Himachal Pradesh. Indian J Chest Dis Allied Sci. 2004 Jan-Mar;46(1)17-22. [Crossref]

05. Rafael Lozano, Mohsen Naghavi, Kyle Foreman, Stephen Lim, Kenji Shibuya, Victor Aboyans, et al. Global and regional mortality from 235 causes of death for 20 age groups in 1990 and 2010- a systematic analysis for the Global Burden of Disease Study 2010. The lancet. 2012;380(9859)2095-128.

Doi: $10.1016 /$ S0140-6736(12)61728-0 [Crossref]

06. Ritesh Sharma, Ram Deoskar, Medha Bargaje, Prashant Kumar, Yogesh Agarwal. A study of etiological and clinical profile of community acquired pneumonia in a tertiary care hospital in Western India. European Respiratory Journal. 2013;42(57)P2766.

[Crossref]

07. Guest JF, Morris A. Community-acquired pneumonia- the annual cost to the National Health Service in the UK. Eur Respir J. 1997 Jul;10(7)1530-4.

[Crossref]

08. Lim WS, van der Eerden MM, Laing $R$, et al. Defining community acquired pneumonia severity on presentation to hospital- an international derivation and validation study. Thorax. 2003 May;58(5)377-82.

DOI: $10.1136 /$ thorax.58.5.377 [Crossref]

09. Fine MJ, Auble TE, Yealy DM, et al. A prediction rule to identify low-risk patients with community-acquired pneumonia. N Engl J Med. 1997 Jan 23;336(4)243-50.

[Crossref]

10. Ewig $S$, de Roux $A$, Bauer $T$, et al. Validation of predictive rules and indices of severity for community acquired pneumonia. Thorax. 2004 May;59(5)421-7.

DOI: $10.1136 /$ thx.2003.008110 [Crossref]
11. Capelastegui A, España PP, Quintana JM, et al. Validation of a predictive rule for the management of community-acquired pneumonia. Eur Respir J. 2006 Jan;27(1)151-7. [Crossref]

12. Aujesky D, Auble TE, Yealy DM, et al. Prospective comparison of three validated prediction rules for prognosis in communityacquired pneumonia. Am J Med. 2005Apr;118(4)384-92.

DOI:10.1016/j.amjmed. 2005.01.006 [Crossref]

13. Warren JL, Bacon WE, Harris $T$, et al. The burden and outcomes associated with dehydration among US elderly, 1991. Am J Public Health. 1994 Aug;84(8)1265-9.

DOI: 10.2105/ajph.84.8.1265 [Crossref]

14. Loh LC, Khoo SK, Quah SY, et al. Adult community-acquired pneumonia in Malaysiaprediction of mortality from severity assessment on admission. Respirology. 2004 Aug;9(3)37986.

DOI: $10.1111 / \mathrm{j} \cdot 1440-1843.2004 .00604 . x$ [Crossref]

15. Buising $\mathrm{KL}$, Thursky $\mathrm{KA}$, Black JF, et al. $A$ prospective comparison of severity scores for identifying patients with severe community acquired pneumonia- reconsidering what is meant by severe pneumonia. Thorax. 2006 May;61(5)419-24.

[Crossref]

16. Ewig S, Kleinfeld T, Bauer T, et al. Comparative validation of prognostic rules for communityacquired pneumonia in an elderly population. Eur Respir J. 1999 Aug;14(2)370-5.

[Crossref]

17. Rosón B, Carratalà J, Dorca J, et al. Etiology, reasons for hospitalization, risk classes, and outcomes of community-acquired pneumonia in patients hospitalized on the basis of conventional admission criteria. Clin Infect Dis. 2001 Jul 15;33(2)158-65.

DOI: $10.1086 / 321808$ [Crossref]

18. Khan Y, Pednekar S, Pandey D. Pneumonia Severity Index In Predicting Outcome In Elderly Patients With Community Acquired Pneumonia At A Tertiary Level Hospital In Mumbai. Ann Int Med Res. 2018;4(3)ME47-ME51.

[Crossref] 